\title{
Informal Employment, Labour Markets and Social Protection: Some Considerations Based on South African Estimates
}

\author{
Imraan Valodia
}

\begin{abstract}
1 Introduction
Since its 'discovery' in the early 1970s by Keith Hart (1973), the informal sector has often been viewed as a sphere of the economy that is distinct from the formal sector. There have, of course, been a number of insightful contributions (e.g. Tokman 1978) highlighting the linkages between the formal and informal spheres of the economy. In the policy arena, however, it is often the case that these are seen as two distinct, and unrelated aspects of the economy. In this article, based on evidence from South Africa, it is suggested that a deeper and more systematic analysis of the nature of economic linkages between the formal and informal economies is critical for appropriate policy responses to the changes occurring in labour markets, particularly the growth in informal employment.
\end{abstract}

There are two strands of the literature on the informal sector that do consider the issue of relationship between the formal and informal. First, that concerned with defining the informal sector, which often defines the informal sector in relation to formal sector enterprises. The informal sector is easier to enter, has smaller enterprises using different and more indigenous technologies and is less skilled and regulated than the formal sector. Second, and related, the literature has been concerned with the structural relationship of the informal sector in relation to the rest of the economy. In the 1970s, Marxists were concerned with whether the informal economy constituted a reserve army, or was 'petty commodity production'. More recently, with the growing interest in microentrepreneurship especially among neoliberal economists, the emphasis has been on issues of regulations in the formal sector and the growth of budding entrepreneurs in the informal economy, supposedly free of the regulatory burden that exists in the formal sector.

The emphasis in this article is not on these longterm structural relationships. Rather, using South African data, it explores short-term economic interactions, movements and linkages between the formal and informal sectors. The ILO (2002) estimates that informal employment typically comprises somewhere between 50 and 75 per cent of non-agricultural employment in developing countries. It is suggested here that the interactions and linkages between formal and informal work need to be more central to the social protection policy agenda in developing countries.

\section{South African examples}

Tables 1 and 2 provide some context for understanding informal work in South Africa. Notwithstanding the growth in informal work in the recent period, South Africa's informal sector, at 19 per cent of total employment, is relatively low compared with other developing countries. The estimates for South Africa are based on the enterprise-based definition of informality (i.e. is the enterprise registered or not). Table 2 however, shows that large numbers of workers employed in formal enterprises earn very low wages, and probably have employment conditions that may be considered 'informal'. Thus, based on the 'employment based' definition (i.e. is the job formal or informal) recommended by the International Conference of Labour Statisticians, the informal economy in South Africa is much larger. 
Table 1 South Africa: distribution of employed by sector (\%)

\begin{tabular}{lcccccc}
\hline & $\mathbf{2 0 0 0}$ & $\mathbf{2 0 0 1}$ & $\mathbf{2 0 0 2}$ & $\mathbf{2 0 0 3}$ & $\mathbf{2 0 0 4}$ & $\mathbf{2 0 0 5}$ \\
\hline Formal agriculture & 6 & 6 & 7 & 7 & 5 & 5 \\
Formal & 57 & 63 & 63 & 64 & 66 & 64 \\
Informal & 15 & 16 & 14 & 15 & 15 & 19 \\
Informal agriculture & 9 & 4 & 5 & 3 & 4 & 3 \\
Domestic & 10 & 10 & 9 & 10 & 9 & $\mathbf{1 0 0}$ \\
Total & $\mathbf{1 0 0}$ & $\mathbf{1 0 0}$ & $\mathbf{1 0 0}$ & $\mathbf{1 0 0}$ & $\mathbf{1 0 0}$ \\
Source Author's calculations from Labour Force Surveys (LFSs).
\end{tabular}

Table 2 Low-waged work by sector, 2004

\begin{tabular}{lll}
\hline Sector & $\begin{array}{l}\text { Percentage of workers earning } \\
\text { SR2,500 ( US\$35) }\end{array}$ & $\begin{array}{l}\text { Percentage of workers earning } \\
\text { SR1,000 ( US\$150) }\end{array}$ \\
\hline Formal & 44.4 & 14.6 \\
Commercial agriculture & 91.4 & 78.5 \\
Subsistence agriculture & 98.0 & 95.6 \\
Informal & 88.7 & 69.6 \\
Domestic work & 99.1 & 87.0 \\
Source Valodia et al. (2006: 100). & & \\
\hline
\end{tabular}

Table 3 Labour market status, February 2002 to March $2004(n=5,587)$

\begin{tabular}{lcc}
\hline Type of worker & Frequency & (\%) \\
\hline Remained in the formal economy & 1,175 & 21.0 \\
Remained economic inactive & 1,077 & 19.3 \\
Remained in commercial agric. & 99 & 1.8 \\
Remained as a domestic worker & 89 & 1.6 \\
Remained unemployed & 74 & 1.3 \\
Remained as informal worker & 71 & 1.3 \\
Worker status changed & 3,002 & 53.7 \\
& $\mathbf{5 , 5 8 7}$ & $\mathbf{1 0 0}$ \\
Source &
\end{tabular}

The panel component of the South African Labour Force Survey (LFS) allows us to explore dynamics in the labour market. The sampling design of the LFS, which is conducted bi-annually in March and September, allows for 80 per cent of the sampling in each wave to remain in the sample. Drawing on Valodia et al. (2006), we explore these dynamics beginning in February ${ }^{1}$ 2002, for five waves of the LFS, ending in March 2004. Matching the individuals in these households over the period, we are able to get some indication of the extent to which workers move between employment and unemployment, and when employed, between different segments of the economy, such as formal and informal. ${ }^{2}$ In total, we were able to match 5,587 individuals over the period.

There are a number of reasons why the analysis presented here needs to be treated with some caution. First, the panel component of the LFS is designed to track households, not individuals. Second, a fairly simple filter was applied, to decide whether or not individuals in tracked households are in fact 
Table 4 Labour market status of informal economy workers, February 2002-March 2004 ( $n=1,009)$

\begin{tabular}{lcr}
\hline Type of worker & Frequency & (\%) \\
\hline Informal for 5 periods & 71 & 7.0 \\
Informal for 4 periods & 88 & 8.7 \\
Informal for 3 periods & 106 & 10.5 \\
Informal for 2 periods & 202 & 20.0 \\
Informal for 1 period & 542 & 53.7 \\
& $\mathbf{1 , 0 0 9}$ & 100 \\
Source Author's calculations from various LFSs.
\end{tabular}

Table 5 Shifts between informal work and other labour market status

\begin{tabular}{lcc}
\hline Type of change & Frequency & (\%) \\
\hline Informal and unemployed and not economically active & 191 & 18.9 \\
Informal and not economically active & 190 & 18.8 \\
Informal and formal & 185 & 18.3 \\
Informal, formal and unemployed & 77 & 7.6 \\
Informal, formal and not economically active & 73 & 7.2 \\
Remained in informal & 71 & 7.0 \\
Informal and unemployed & 60 & 5.9 \\
Informal, formal, unemployed and not economically active & 44 & 4.4 \\
Other & 118 & 11.7 \\
& $\mathbf{1 , 0 0 9}$ & $\mathbf{1 0 0}$
\end{tabular}

Table 6 Movements between formal and informal jobs, 2001-4

\begin{tabular}{lc}
\hline $\begin{array}{l}\text { Movements between formal } \\
\text { and informal }\end{array}$ & $\begin{array}{c}\text { No of } \\
\text { occurrences }\end{array}$ \\
\hline FFFFI & 39 \\
FFFIF & 14 \\
FFIFF & 20 \\
IFFFF & 19 \\
Other & 93 \\
Total & 185 \\
Source Author's calculations from various LFSs.
\end{tabular}

the same individual. The sex and age profiles of workers in these households were examined, to confirm that the individuals remain in the panel. Thus, removed from the panel are all households where the individuals inside the household may have changed (through, e.g. migration). Third, although the panel of 5,587 workers is fairly large, based on the number of households surveyed in the LFS, we ideally should have a larger panel. Fourth, although the initial estimates suggest that the sample of households in the panel is similar to that of the LFS, ${ }^{3}$ further analysis of this needs to be done.

Notwithstanding these concerns, the author believes that, even at this preliminary level, the panel analysis raises some interesting questions about the relationships between formal and informal employment in South Africa.

Table 3 gives a broad overview of how the status of these workers changed over the period. The data shows that there is a surprising level of churning within the labour market, with more than half of the workers' status having changed at least once over the period February 2002 to March 2004. As is to be expected, for those workers whose status remained unchanged, that most tended to be employed in the formal sector, or remained economically inactive. Only 1.3 per cent of the 5,587 workers that remained in the panel continued to work in the informal economy over the period under consideration. 
Table 7 FFFFI workers - monthly incomes over the panel, September 2001-3 by income band

\begin{tabular}{|c|c|c|c|c|}
\hline 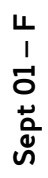 & $\begin{array}{l}4 \\
1 \\
\text { ̃ } \\
\text { D } \\
\frac{\pi}{\Sigma}\end{array}$ & 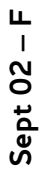 & 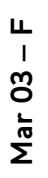 & 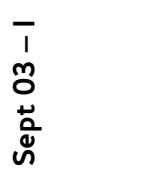 \\
\hline \multirow[t]{4}{*}{4} & 5 & 5 & 6 & 6 \\
\hline & 13 & 13 & & 9 \\
\hline & & 9 & 10 & 9 \\
\hline & & 9 & 10 & 9 \\
\hline 8 & 8 & 8 & 8 & 9 \\
\hline 7 & 6 & 7 & 6 & 6 \\
\hline \multirow[t]{2}{*}{9} & 12 & 9 & 8 & 9 \\
\hline & 11 & 10 & 10 & 10 \\
\hline 4 & 4 & 6 & 6 & 7 \\
\hline 9 & 9 & 9 & 9 & 9 \\
\hline 5 & 6 & 7 & 7 & 7 \\
\hline 9 & 11 & 9 & 9 & 10 \\
\hline 2 & & 3 & & \\
\hline 3 & 6 & 8 & 6 & 5 \\
\hline 1 & 3 & 3 & 3 & 3 \\
\hline 4 & 4 & 4 & & 4 \\
\hline 8 & 7 & 10 & 8 & \\
\hline 8 & 8 & 7 & 8 & 5 \\
\hline 4 & 4 & 3 & 6 & 6 \\
\hline 2 & 3 & 3 & 4 & 4 \\
\hline 6 & 4 & 7 & 5 & 5 \\
\hline 4 & 4 & 7 & 5 & 4 \\
\hline 9 & 11 & & & \\
\hline 11 & 11 & 12 & & \\
\hline 9 & 7 & 7 & & \\
\hline 7 & 9 & 9 & 7 & 7 \\
\hline 10 & 11 & 10 & 11 & 10 \\
\hline 10 & 10 & 11 & 11 & 11 \\
\hline 2 & 5 & 4 & 4 & 4 \\
\hline 6 & 5 & 7 & 6 & 6 \\
\hline 6 & 6 & 7 & 11 & \\
\hline 5 & 5 & 5 & 5 & 6 \\
\hline 7 & 4 & 4 & 4 & 5 \\
\hline 4 & 4 & & 6 & 6 \\
\hline 9 & 7 & 8 & 5 & 9 \\
\hline 2 & 6 & 6 & 6 & 6 \\
\hline 3 & 4 & 4 & 4 & 6 \\
\hline 3 & & 6 & 4 & 4 \\
\hline 4 & 4 & 4 & 4 & 4 \\
\hline \multicolumn{5}{|c|}{$\begin{array}{l}\text { The income bands, expressed in rands, are as follows } \\
1=\text { None, } 2=1-200,3=201-500,4=501-1000 \text {, } \\
5=1,001-1,500,6=1,501-2,500,7=2,501-3,500, \\
8=3,501-4,500,9=4,501-6,000,10=6,001-8,000 \text {, } \\
11=8,001-11,000,12=11,001-16,000 \text {, } \\
13=16,001-30,000,14=30,000+. \\
\text { Source Author's calculations from various LFSs. }\end{array}$} \\
\hline
\end{tabular}

Table 8 IFFFF workers - monthly incomes over the panel, September 2001-3 by income band

\begin{tabular}{|c|c|c|c|c|}
\hline $\begin{array}{l}\overline{1} \\
\overrightarrow{0} \\
\stackrel{2}{a} \\
\dot{\Delta}\end{array}$ & $\begin{array}{c}\text { L } \\
\text { I } \\
\text { N } \\
0 \\
\frac{1}{\mathbf{T}} \\
\Sigma\end{array}$ & 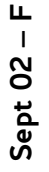 & 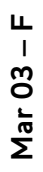 & 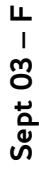 \\
\hline 6 & 5 & 4 & 5 & 5 \\
\hline 7 & & 7 & 8 & 7 \\
\hline 9 & & 7 & 7 & 2 \\
\hline 6 & 6 & 6 & 7 & 4 \\
\hline 4 & 4 & 4 & 4 & 4 \\
\hline 3 & 4 & 4 & 4 & 4 \\
\hline 4 & 4 & 4 & 4 & 4 \\
\hline 3 & 3 & 2 & 3 & 3 \\
\hline 4 & 4 & 4 & 6 & 4 \\
\hline 5 & 5 & 5 & 5 & 5 \\
\hline \multirow[t]{3}{*}{4} & 5 & 5 & 6 & 6 \\
\hline & 10 & 10 & & \\
\hline & 5 & 5 & & 5 \\
\hline 6 & 9 & 8 & 8 & 8 \\
\hline \multirow[t]{2}{*}{5} & 6 & & 8 & 6 \\
\hline & 9 & 8 & 8 & \\
\hline 3 & 4 & 4 & 4 & 4 \\
\hline 5 & 6 & 5 & 6 & \\
\hline 5 & 3 & 4 & 4 & 3 \\
\hline
\end{tabular}

See Table 7 for income bands. Source Various LFSs.

Table 4 removes from the panel all workers who did not engage in informal economy activities over the period, i.e. it retains only workers who have been engaged in informal economy activities for at least one period. This reduces the number of workers from 5,587 to 1,009 . Again, we see a surprising level of churning occurring, with only 7 per cent of workers remaining as informal workers over the entire period.

Table 5 shows the movement of workers that were employed in the informal economy in any one period over the panel. As is to be expected, a large number of workers moved between the informal economy and being unemployed or economically inactive. $A$ significant proportion of workers (18.3 per cent) moved between formal and informal employment.

If we reduce the period under consideration to just six months, from February 2002 to September 2002, i.e. over a 6-month period, we still find fairly high levels of churning in the labour market. Of individuals recorded as informal workers in March 2003, in 
Table 9 Competition between formal and informal retailers

\begin{tabular}{llcccc}
\hline \multicolumn{5}{c}{ Formal retail stores } \\
\cline { 3 - 6 } & \multicolumn{2}{c}{ Very important } & Important & Not important & Total informal \\
\hline \multirow{2}{*}{$\begin{array}{l}\text { Other informal } \\
\text { traders }\end{array}$} & Very important & 33 & 10 & 18 & 61 \\
& Important & 5 & 2 & 9 & 16 \\
& Not important & 10 & 2 & 11 & $\mathbf{3 8}$ \\
\cline { 3 - 5 } & Total retail & $\mathbf{4 8}$ & $\mathbf{1 4}$ & $\mathbf{3 8 0}$ \\
Source Valodia et al. (2007). & & & & \\
\hline
\end{tabular}

September 2003, 44.5 per cent reported working in informal economy; 17.3 per cent reported working in formal economy; 11.4 per cent reported being unemployed; and 23.7 per cent reported being not economically active. Of individuals recorded as formal workers in March 2003, in September 2003, 3.4 per cent reported working in the informal economy.

Income data in the LFS was exploited to explore some of the income dynamics related to movements between the formal and informal sectors. In particular, we explore below the shifts of the 185 movements between formal and informal reported in Table 6 . Given that we are dealing with a 5-period panel, there are a large number of formal and informal movements that are possible. In order to keep the analysis manageable, we focus only on some movements. Table 6 summarises the movements that will be explored. The first, FFFFI, which occurs 39 times in the panel, shows workers that reported being in formal jobs over the LFSs, February 2002 to September 2003 (i.e. four surveys) and then shifted to an informal job in the last period of the panel, March 2004. Similarly, the second, FFFIF, which occurs 14 times, shows workers in formal jobs over the initial three surveys, move into an informal job in the fourth period (September 2003) but then move back into a formal job in March 2004.

Using the LFS income bands, ${ }^{4}$ and excluding nonresponses, Table 7 shows the incomes of the FFFFI workers over the period of the panel. We see very little change in workers' incomes over the 4th and 5th periods of the panel, when the worker shifts from formal to informal employment. Similarly, Table 8, which shows the incomes for IFFFF movements, shows very little change in incomes over the lst and 2nd periods when the worker moves from informal to a formal employment. Although not reported in the article, shifts in incomes are relatively minor for the other combinations of formal and informal work over the five periods under consideration.

Although these data may have high levels of error, ${ }^{5}$ both in terms of the formal and informal classification and in terms of the incomes reported, the data suggests two important characteristics of formal-informal linkages. First, at the low end of the labour market, in what we have called low-waged work, the South African data suggests high levels of churning between formal and informal employment over a relatively short period of time. This suggests that, low-waged workers are unlikely to benefit significantly from shifting from informal to formal employment, and vice-versa. Second, unlike the case in Latin America where Maloney (2004) and others have argued that workers choose to move into the informal sector to escape onerous legislative requirements. There are two arguments that appear to counter this free-choice view. First, the movements occur in both directions, not just formal to informal which one would expect if the freechoice view dominates. Second, as these gross incomes above suggest, there seems to be very little, if any, economic benefits associated with movements from formal to informal employment.

My second example of the linkages between the formal and informal spheres of the economy is concerned about micro-level market relationships and interactions between formal and informal enterprises. To the best of my knowledge, this is an underdeveloped area in the literature. In collaborative research with the Human Sciences Research Council in South Africa (see Valodia et al. 2007) to begin to understand economic relationships between formal and informal enterprises, we conducted a pilot survey of 100 informal traders in the city of Durban to 
examine the nature of the linkages between informal enterprises, and between formal and informal enterprises.

Table 9 explores the price setting behaviour of informal traders. The responses could be interpreted as giving some indication of the level of competition that the traders thought they faced from other informal retailers and from formal retailers. $A$ total of 33 per cent of the sample saw both formal and informal prices as very important to their own price setting and 11 per cent set their prices seemingly independent of external price considerations. Some 48 of the 100 respondents saw formal prices as very important, 10 of whom did not view informal prices as important. In contrast, of the 61 traders that viewed other informal prices to be very important, 18 did not deem formal prices to be very important. This provides us with some useful insights into economic behaviour in informal enterprises, and suggests that there are important linkages and relationships between economic decision-making in formal and informal enterprises.

\section{Social protection - some considerations}

This article has presented some, admittedly preliminary, data for South Africa which suggests very important linkages between the formal and informal sectors. Specifically, this data suggests that among workers that

\section{Notes}

1 The LFS used to be conducted in February before 2003.

2 Note that the panel component of the LFS allowed us to track households not individuals over the five waves of the survey. The sex and age profiles of workers in these households were examined to confirm that the individuals remain in the panel. Thus removed from the panel were all households where the individuals inside the household may have changed (through, e.g. migration).

\section{References}

Hart, K. (1973) 'Informal Income Opportunities and Urban Employment in Ghana', Journal of Modern African Studies 11.1: 61-89

International Labour Organisation (ILO) (2002) Women and Men in the Informal Economy: $A$ Statistical Picture, Geneva: ILO

Maloney, W.F. (2004) 'Informality Revisited', World Development 32.7: 1159-78

Tokman, V. (1978) 'An Exploration into the Nature of earn low-wages, there is a surprisingly high level of labour market churning - movements, in a relatively short time, between formal and informal jobs. There are also important economic relationships that exist between formal and informal enterprises. These, it is suggested, are substantially more complex than simple backward and forward supply relationships. There are important relationships affecting economic behaviour, such as price-setting, between formal and informal enterprises. In conclusion, some implications for social protection are proposed.

First, the high levels of churning suggest that there are in fact high levels of insecurity and flexibility in the low-waged segment of the South African labour market. The notion therefore that formal employment gives workers access to other social protection measures is clearly not the case in South Africa, and probably elsewhere. Second, although we were unable to verify this (this data does not allow this), the high levels of churning may be the result of low-waged workers having multiple livelihood and income strategies to deal with the high levels of insecurity. Often, the discussions about social protection do not sufficiently consider this possibility. Third, and related, to be effective for those earning low-wages, social protection mechanisms have to be flexible enough to cater for rapid and frequent movements between formal and informal activity.

3 For example, the sex, race and employment patterns in the panel are similar to that of the LFS. However, there are some spatial differences.

4 The income bands in Rands $(R)$ are as follows: 1=None, 2=R1-R200, 3=R201-500, 4=R501-1000, 5=R1,001-1,500, 6=R1,501-2,500, $7=R 2,501-3,500,8=R 3,501-4,500$, 9=R4,501-6,000, 10=R6,001-8,000, $11=R 8,001-11,000,12=R 11,001-16,000$, $\mathrm{R} 13=16,001-30,000, \mathrm{R} 14=30,000+$.

5 These will be explored in ongoing work.

Informal-formal Sector Relationships', World Development 6.9/10: 1065-75

Valodia, I., Davies, R., Altman, M. and Thurlow, J. (2007) Exploring Economic Behaviour in South Africa's Informal Economy, Especially in Relation to the Formal Economy, Pretoria: Human Sciences Research Council

Valodia, I., Lebani, L., Skinner, C. and Devey, R. (2006) 'Low-waged and Informal Employment in South Africa', Transformation 60: 90-126 